\title{
Wound care management: tracheostomy and gastrostomy
}

\author{
Sammar Alsunaid ${ }^{1}$, Van K. Holden ${ }^{1}$, Akshay Kohli ${ }^{2}$, Jose Diaz ${ }^{3}$, Lindsay B. O'Meara ${ }^{3}$ \\ ${ }^{1}$ Division of Pulmonary \& Critical Care Medicine, Section of Interventional Pulmonology, University of Maryland School of Medicine, Baltimore, \\ MD, USA; ${ }^{2}$ Department of Internal Medicine, Medstar Washington Hospital Center, Georgetown University, Washington, DC, USA; ${ }^{3}$ Division of \\ Acute Care Emergency Surgery, University of Maryland Medical Center, Baltimore, MD, USA \\ Contributions: (I) Conception and design: S Alsunaid, A Kohli; (II) Administrative support: S Alsunaid; (III) Provision of study materials or patients: \\ None; (IV): Collection and assembly of data: All authors; (V) Data analysis and interpretation: All authors; (VI) Manuscript writing: All authors; (VII) \\ Final approval of manuscript: All authors. \\ Correspondence to: Sammar Alsunaid, MD. Division of Pulmonary \& Critical Care Medicine, 110 S. Paca Street, 2nd Floor, Baltimore, MD, USA. \\ Email: salsunaid@som.umaryland.edu.
}

\begin{abstract}
Percutaneous dilatational tracheostomy (PDT) and percutaneous endoscopic gastrostomy (PEG) tube placements are routine procedures performed in the intensive care units (ICUs). They are performed to facilitate care and promote healing. They also help prevent complications from prolonged endotracheal intubation and malnutrition. In most cases, both are performed simultaneously. Physicians performing them require knowledge of local anatomy, tissue and vascular relationships, along with advance bronchoscopy and endoscopy skills. Although PDTs and PEGs are considered relatively low-risk procedures, operators need to have the knowledge and skill to recognize and prevent adverse outcomes. Current published literature on post-procedural care and stoma wound management was reviewed. Available recommendations for the routine care of tracheostomy and PEG tubes are included in this review. Signs and symptoms of early PDTand PEG-related complications and their management are discussed in detail. These include hemorrhage, infection, accidental decannulation, tube obstruction, clogging, and dislodgement. Rare, life-threatening complications are also discussed. Multidisciplinary teams are needed for improved patient care, and members should be aware of all pertinent care aspects and potential complications related to PDT and PEG placement. Each institute is strongly encouraged to have detailed protocols to standardize care. This review provides a state-of-the-art guidance on the care of patients with tracheostomies and gastrostomies specifically in the ICU setting.
\end{abstract}

Keywords: Critical care; gastrostomy; nursing care; tracheostomy; wounds

Submitted Feb 24, 2020. Accepted for publication Apr 27, 2020.

doi: 10.21037/jtd-2019-ipicu-13

View this article at: http://dx.doi.org/10.21037/jtd-2019-ipicu-13

\section{Introduction}

Percutaneous dilatational tracheostomy (PDT) and percutaneous endoscopic gastrostomy (PEG) placement are well-studied, commonly performed procedures in intensive care units (ICUs). In recent years, interventional pulmonologists have started performing these procedures due to their experience in airway management, advance endoscopy skills, and knowledge of tracheal anatomy (1).
Approximately $10-15 \%$ of patients requiring mechanical ventilation will ultimately undergo tracheostomy (2). In a large prospective cohort study, up to $34 \%$ of patients who required mechanical ventilation for more than 48 hours needed tracheostomy placement (3). More than half of the patients who underwent tracheostomy also required PEG placement for prolonged nutritional needs $(4,5)$. In this article, we review appropriate post-procedural care for PDT and PEG, as well as possible complications that can develop. 

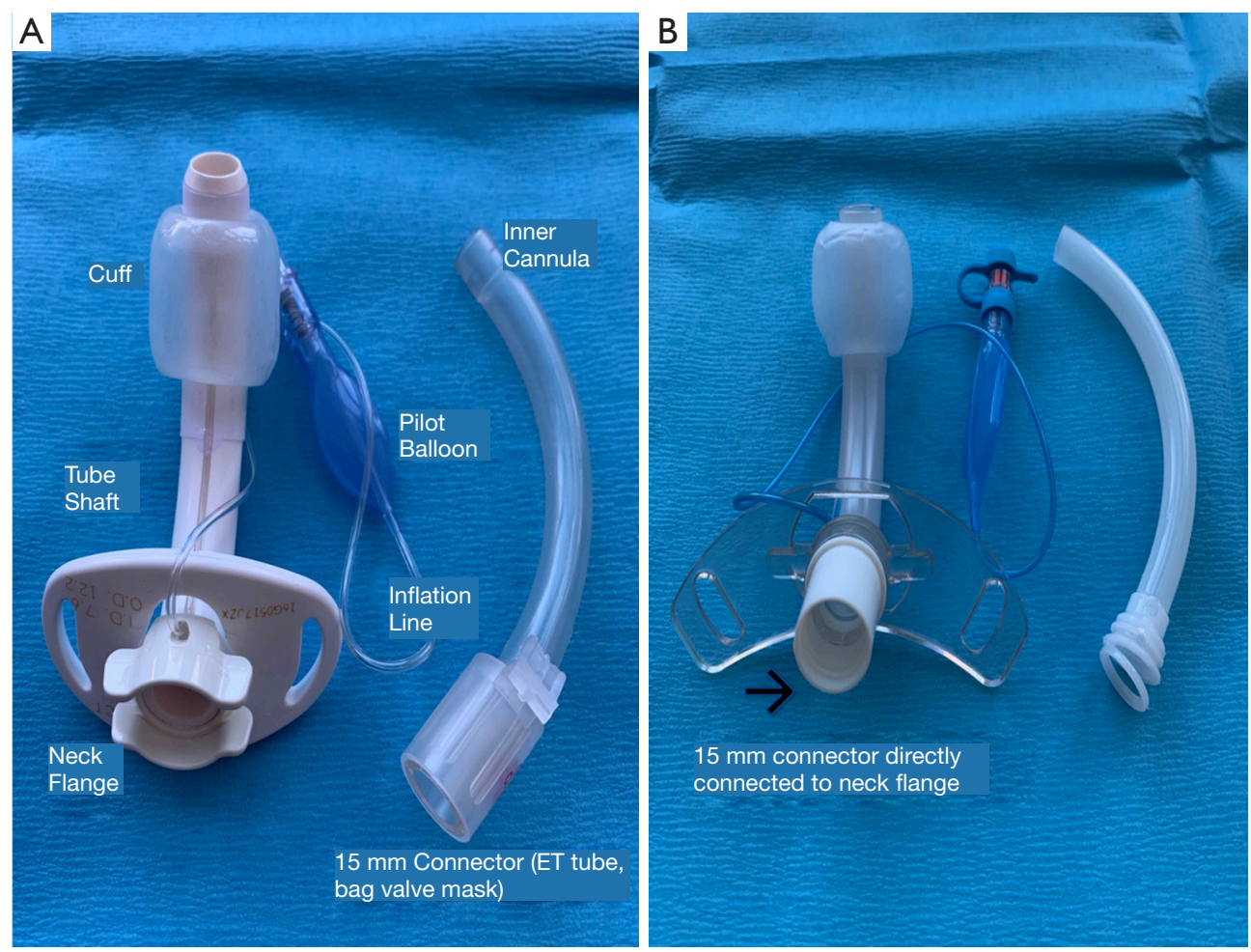

Figure 1 Different tracheostomy tubes. (A) Shiley ${ }^{\mathrm{TM}}$ 8DCT (7.6 mm I.D., $12.2 \mathrm{~mm}$ O.D., $79 \mathrm{~mm}$ L), inner cannula is required for connection to ventilator or bag-mask-valve devices; (B) Portex ${ }^{\circledR}$ Bivona ${ }^{\circledR}$ TTS (8.0 mm I.D., 11.0 O.D, 88 mm L), similar structure to (A), ventilator or bag-valve-mask devices connect directly to the tube (inner cannula not required for connection). DCT, disposable cuffed tracheostomy tube; I.D., inner diameter; O.D., outer diameter; L, length; TTS, tight to shaft.

\section{Tracheostomy}

Tracheostomy is a surgical procedure that has been mentioned throughout history, with the earliest documentation of a successful tracheostomy by Italian physician Antonio Brasavola in 1546 (6). The procedure was transformed when Ciaglia introduced the PDT method in 1985 (7). In a recent review evaluating 22 studies with a total of 1,608 patients [813 PDT, 795 open surgical tracheostomy (ST)], there was no statistically significant difference between PDT and ST in rates of mortality, intra-operative hemorrhage, and post-operative hemorrhage. However, there was a statistically significant difference favoring PDT in decreasing infection risk and procedure time (8). Similarly, a Cochrane review concluded no difference in rates of mortality directly related to the procedure, serious life-threatening intra-operative adverse events, major bleeding, tracheostomy tube occlusion, or accidental decannulation. It also corroborated that PDT had lower rates of wound infection and unfavorable scarring (9).
Currently, PDT is the recommended first-line approach when tracheostomy is needed in ICU patients with ST reserved as an alternative procedure by most current guidelines $(10,11)$.

Tracheostomy tubes are placed for a variety of reasons, including respiratory failure, airway obstruction, airway protection, and inability to manage secretions (12). They are made of various materials, most commonly silicone or polyvinyl chloride (PVC). Metal tracheostomy tubes are also available and can be utilized for long-term tracheostomies in stable non-ventilated patients. However, they are not commonly used due to their expense, rigid construction, and lack of a cuff (13). Regardless of the manufacturer, tracheostomy tubes share common features: the dimensions are given by the inner diameter (I.D.), outer diameter (O.D.), length, and curvature. These numbers are often marked on the flange. Tubes can be cuffed or uncuffed, and some may be fenestrated. They may also include a removable inner cannula, referred to as dualcannula tracheostomy tubes (14) (Figure 1). 


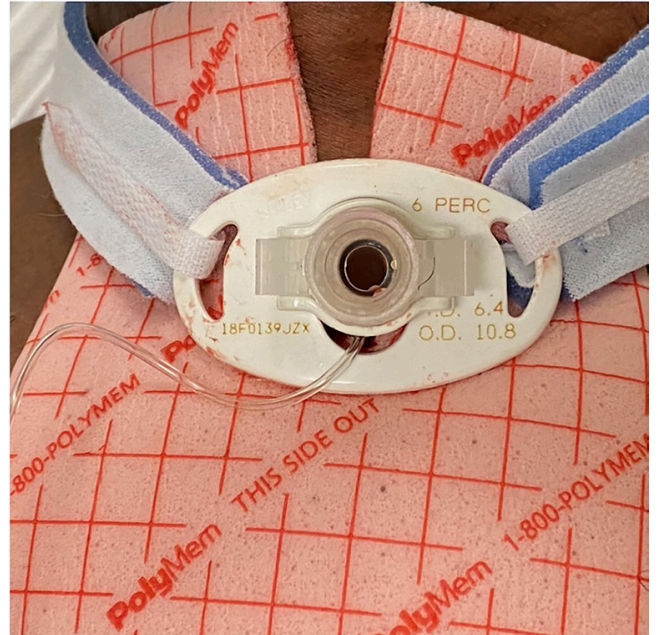

Figure 2 Tracheostomy (size 6DCT Shiley ${ }^{\mathrm{TM}}$ ) with PolyMem ${ }^{\circledR}$.

When placed via the PDT method, a small incision is made in the skin overlying the trachea. Then, a needle is placed into the trachea, and the tract is dilated using a Seldinger technique. This can be done under direct bronchoscopic visualization or ultrasound guidance $(15,16)$. Various techniques are available for ST, which are performed by surgeons most commonly in the operating room and with direct visualization. A common technique is to create a "trap door" (Björk flap) by pulling a small part of the tracheal cartilage inferiorly and suturing it to the skin (17). This is important to recognize as the flap facilitates reinsertion of the tube if accidental decannulation occurs. Regardless of the method, routine care of tracheostomy tubes is required to prevent complications. Nursing staff and respiratory therapists should be educated on proper care techniques, early signs of complications, and initial steps in managing and stabilizing these complications. Each institution should also have its own standard policies and procedures for post-procedural care.

\section{Tracheostomy tube site care}

\section{Stomal site care}

The stomal wound should always be kept clean and dry. The stoma should be cleaned using sterile water or normal saline. If dried secretions are present, cotton-tipped swabs or gauze pads with sterile saline or water can be used to gently remove them. Dried secretions can also be loosened with diluted hydrogen peroxide and rinsed off with saline (18). During cleaning, the site should be inspected for signs of irritation or infection, including erythema, induration, fluctuance, pain and secretion characteristics. It is recommended that a newly placed tracheostomy is inspected every 4-8 hours (19). In patients with copious secretions, frequent dressing changes are necessary to keep the skin dry and prevent maceration of tissue and skin breakdown. The use of barrier creams or solutions such as Cavilon $^{\mathrm{TM}}$ No Sting Barrier Film or Alevyn may be needed (Figure 2).

\section{Suctioning}

Tracheal secretions should be cleared via gentle suctioning in a timely manner. It is important to ensure that the in-line suction catheter has been exchanged to one shorter than that used when the patient was orally or nasally intubated to help prevent deep suction trauma (Figure 3). Suctioning should be limited to the length of the tracheostomy tube. Excessive deep suctioning risks mucosal trauma, whereas inadequate suctioning increases risk of tube blockage (20). Suctioning frequency should be tailored to the patient's needs; however, a standardized frequency of assessment is recommended (12). Suctioning is recommended when there is evidence of visual or audible secretions in the airway and before and after each tracheostomy or inner cannula cleaning and/or change. The use of humidified oxygen is recommended to prevent mucosal dryness and development of thickened secretions (21). Shapiro et al. established that a vital capacity (VC) at least $15 \mathrm{~mL} / \mathrm{kg}$ is optimal for adequate secretion clearance. When the VC or cough reflex is diminished, patients may require more frequent suctioning (22). Overall, patients in the ICU tend to be physically deconditioned, and encouraging mobility and effective coughing can aid in secretion clearance.

In the 1980s, the closed tracheal suctioning system (CTSS) was introduced (Figure 4). It offers several advantages over open suctioning systems, including decreased hypoxia, maintenance of positive endexpiratory pressure, prevention of volume loss, and limited environmental, personnel, and patient contamination. In a comparison of both methods, no significant difference was identified in the incidence of ventilator-associated pneumonia, mortality rate, or ICU length of stay (23). However, a higher incidence of respiratory tract and ventilator tubing bacterial colonization has been reported with the CTSS (24).

Oral secretions should be cleared via a separate suctioning yankauer. The yankauer and suction tubing 

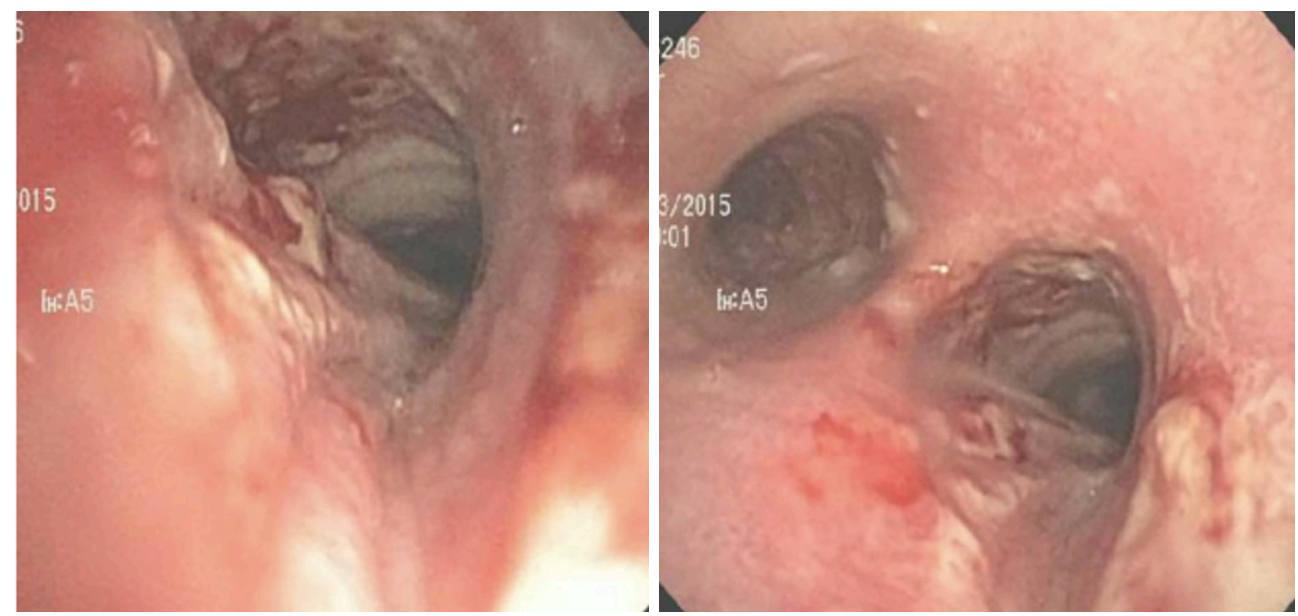

Figure 3 Bronchoscopy showing distal trachea with suction trauma leading to mucosal injury.
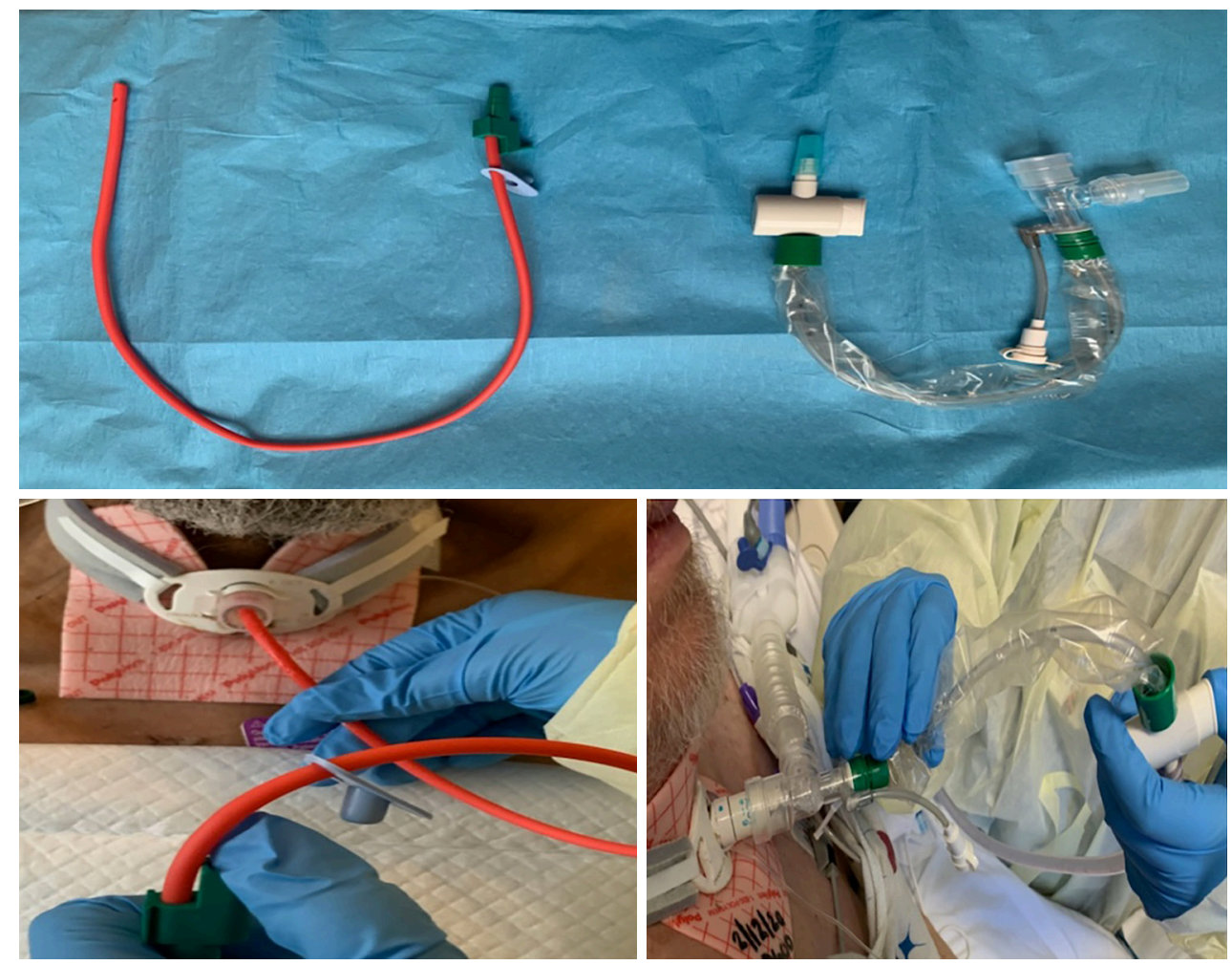

Figure 4 Suction systems. Top: open $v$ s. closed. Bottom: open \& closed systems in use.

should be changed every 24 hours and rinsed as needed to reduce the risk of infection (25).

\section{Tracheostomy ties}

In most ICUs, tracheostomy tubes are secured via tracheostomy-ties (TT) around the patient's neck. A variety of TTs are available, but it is important to ensure that the tracheostomy tube is secured. It is recommended that the ties be secured tightly with room for only one finger breadth between the ties and the patient's neck (12). TTs should be replaced as needed, i.e., if they are visibly soiled 
or if the Velcro loses its effectiveness. In addition, the skin underneath the ties should be inspected regularly.

In patients who are considered high-risk for tracheostomy complications, such as morbidly obese patients, patients with difficult airway anatomy, airway obstruction, or difficult tracheostomy placements, sutures may be used to secure the flange to the neck. Recent literature has demonstrated that removal of all tracheostomy sutures within 7 days of placement helps to reduce hospitalacquired pressure injuries from the flange. Once the sutures are removed, it is recommended that a polyurethane foam be placed under the flange and changed when soiled or with routine tracheostomy care (26).

\section{Inner cannula care}

The purpose of an inner cannula (IC) in most tracheostomy tubes is to prevent tube obstruction by allowing for regular cleaning or replacement. Most PVC ICs are cleaned with solutions of half- or full-strength hydrogen peroxide diluted with sterile water. Some recommend the use of normal saline alone, especially if the IC is made of silicone as it tends to absorb cleaning products. It is important to review the manufacturers' instructions for cleaning of the IC (12). Currently, there are no studies that have evaluated the optimal cleaning frequency of ICs. In general, it is recommended that the reusable IC be inspected and cleaned regularly, at least 3-times per day after initial tracheostomy placement. The frequency may need to be adjusted based on the volume and thickness of secretions. Some ICs are designed to be disposable for ease of use, which can be preferable (12).

Another important function of the IC, which depends on the tracheostomy tube type, is their use as the connector piece to the ventilator or bag-valve mask. This includes the DCT (dual cannula tracheostomy), LPC (low-pressure cuffed), and XLT (extended length) (12).

\section{Tracheostomy tube change}

Currently, there is no evidence to support a standardized timing for tracheostomy tube change. Changes are typically done according to the preference of the provider. Mitchell et al. recommended replacing the initial tracheostomy tube within 10-14 days post-PDT and within 3-7 days post-ST (21). However, the timing may be institutional and provider dependent. It is also recommended that the first change be performed at the facility and that sutures, if present, be removed prior to discharge (21).

Indications for tracheostomy tube change include the need for a different tube size or type, tube malfunction, routine changes for ongoing airway management, and prevention of infection and granulation tissue formation (27). There is limited evidence on the optimal timing for changing of a chronic tracheostomy tube. In one observational study, fewer complications from granulation tissue formation were seen with tube change performed every 2 weeks (28). A Swedish study evaluating 3 different types of polymeric tracheostomy tubes recommended routine tube change every 3 months (29). Most manufacturers (Shiley ${ }^{\circledR}$ PVC tubes, Portex ${ }^{\circledR}$ Blue Line, Porte ${ }^{\circledR}$ Bivona) recommend routine changing of their tubes every 29-30 days (27).

The American Thoracic Society published guidelines in 2000 for the care of children with chronic tracheostomy tubes; however, no similar guidelines are available for adults (30). One article recommended changing PVC tracheostomies every 8 weeks and silicone tubes, every 4 weeks for inpatients and every $8-12$ weeks for outpatients (27). Institutions are encouraged to develop tracheostomy-changing protocols and educate appropriate staff.

\section{Tracheostomy wound-related complications}

Common tracheostomy-related complications include wound site bleeding and infection, skin breakdown, tube obstruction, tube dislodgement, and pressure injury. Other less frequent but highly morbid complications include tracheal stenosis, tracheomalacia, and tracheoesophageal fistula formation (Figure 5). Emergent complications, such as severe hemorrhage due to trachea-innominate fistula (TIF), are rare but associated with high mortality rates.

\section{Bleeding}

A small amount of bleeding is expected after the initial procedure and after tracheostomy tube change. Although this is usually minimal and self-limited, topical agents, such as silver nitrate or Surgicel ${ }^{\circledR}$, are sometimes needed (31) (Figure 6). If the bleeding is more significant or persistent, the team that placed the tracheostomy should be contacted for evaluation. Surgical exploration or vessel ligation may be required in up to $5 \%$ of cases (32).

One of the most severe complications with a reported 

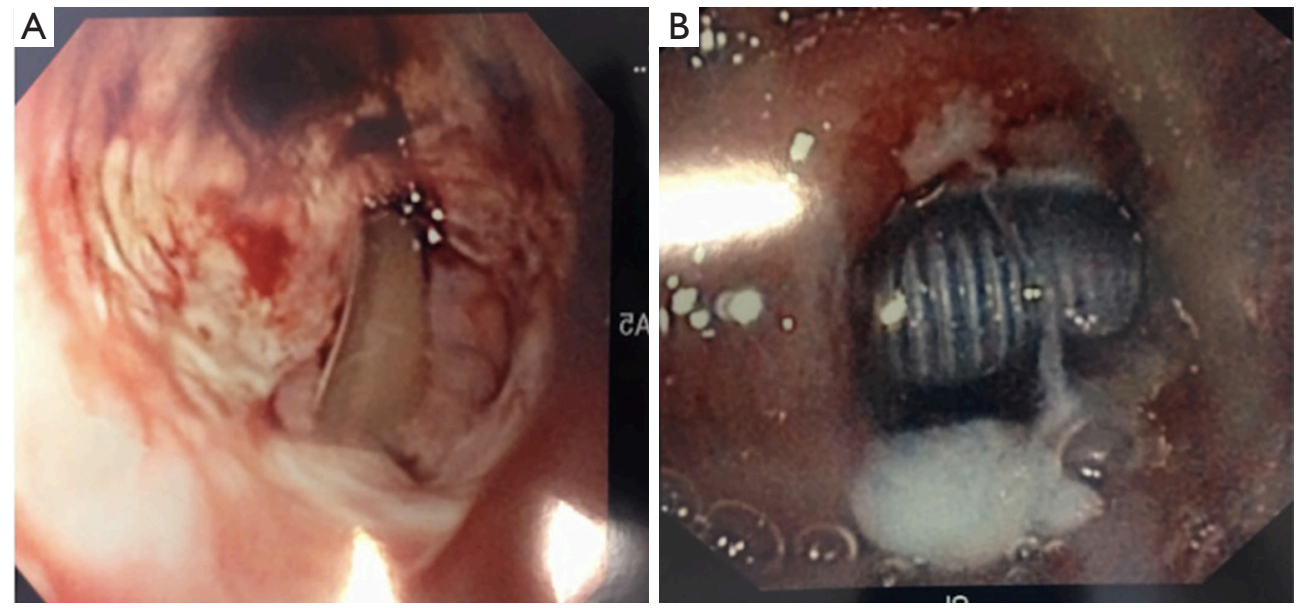

Figure 5 Tracheoesophageal fistula in a patient with sepsis needing prolonged mechanical ventilation. High cuff pressures were documented. (A) Bronchoscopic view showing nasogastric tube visible through the fistula; (B) endoscopic view of the tracheostomy tube in the airway visible through the fistula.
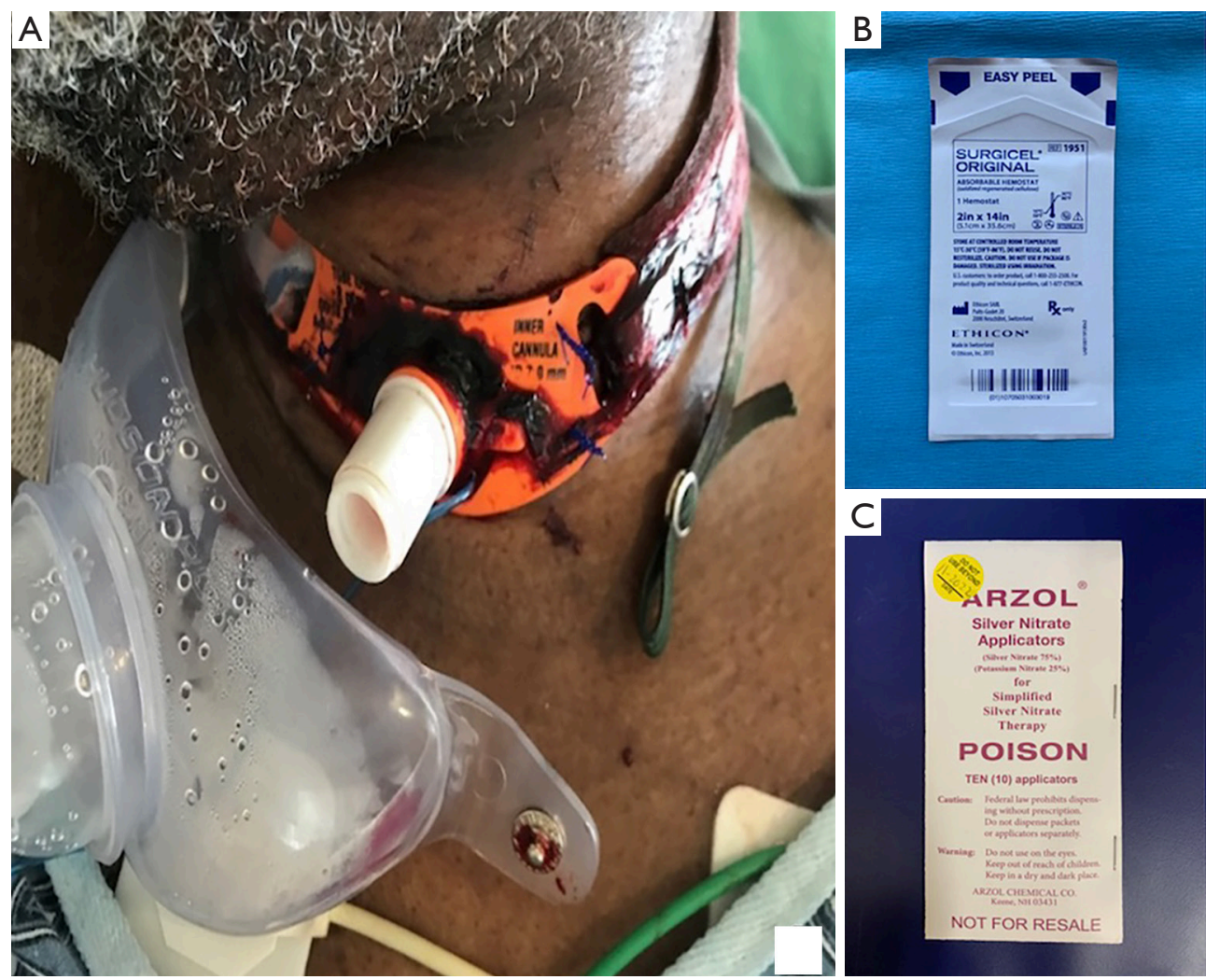

Figure 6 (A) Superficial stomal bleeding requiring application of Surgicel ${ }^{\circledR}$; (B) Surgicel ${ }^{\circledR}$ packet; (C) Silver nitrite packet.

mortality rate of $>75 \%$ is the development of TIF, which is rare with an incidence of $0.7 \%$ (33). Most develop as a result of direct pressure from the tracheostomy tube against the innominate artery. Risk factors for fistula formation include low tracheostomy tube placement, elevated cuff pressure, and excessive head and neck 


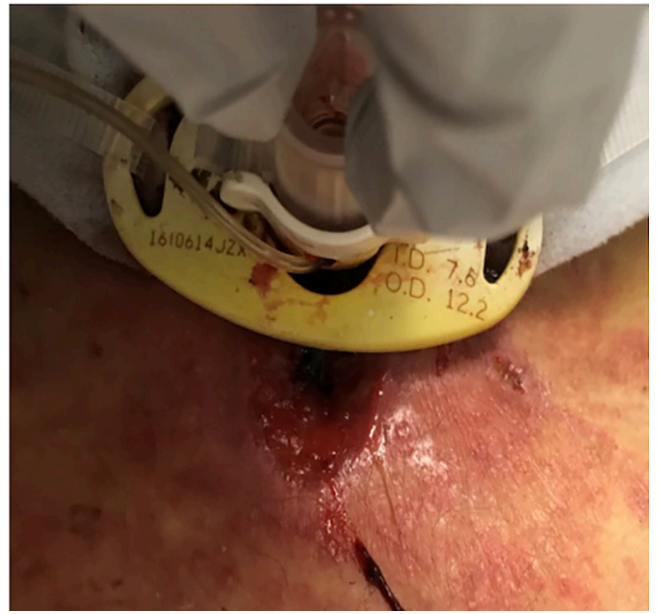

Figure 7 Skin erosion under the tracheostomy flange.

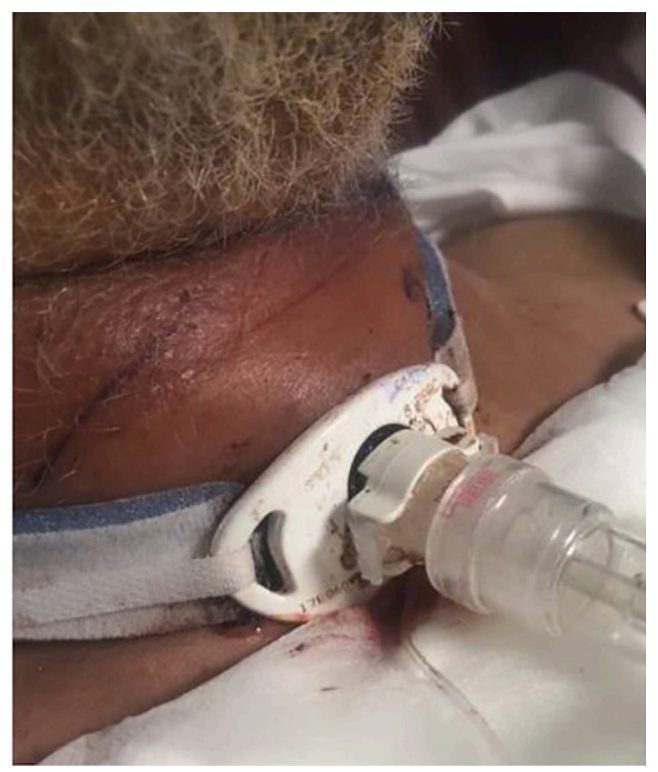

Figure 8 Tracheostomy stomal cellulitis with edema.

movement. Strategies to prevent TIF formation include correct initial tracheostomy placement, avoiding prolonged hyperextension of the neck, avoiding over-inflation of the cuff, and using soft, adjustable, lightweight tracheostomy tubes to avoid dragging (32). A TIF is a surgical emergency, and the performing team along with a surgical team should emergently be notified. Initial stabilizing methods include over-inflation of the cuff or utilizing the Utley maneuver, in which a finger is placed through the incision to apply direct pressure on the artery against the posterior sternum $(34,35)$.

\section{Skin breakdown}

Skin breakdown can occur either from the outward and downward traction against the tube secondary to the weight of the ventilator tubing or the inward pressure from the flange into the neck. The outward traction can lead to skin erosion, tube dislodgement, accidental decannulation, and enlargement of the stoma. Inward traction contributes to skin erosion under the flange (Figure 7). Stoma site inspection, cleaning, and maintaining a dry wound is as important as keeping the neck in a neutral position to minimize these traction forces $(21,32)$. Different dressings are available depending on the underlying condition: gauze drain sponges for minimal to moderate secretions, polyurethane foam $\left(\right.$ Lyofoam $^{\circledR}$ ) for copious secretions, hydrocolloid (DuoDERM ${ }^{\circledR}$ ) for copious secretions with potential or actual skin breakdown, silicone foam $\left(\right.$ Mepilex ${ }^{\circledR}$ ) for similar use to hydrocolloids with the additional indication for cushioning the skin from the flange, and carboxymethylcellulose impregnated with ionic silver (Aquacel $\mathrm{Ag}^{\circledR}$ ) and nylon impregnated with silver $\left(\right.$ Silverlon $^{\circledR}$ ) for local stomal infection (12).

\section{Infection}

The tracheostomy stoma is considered a clean, contaminated wound, and pre-procedure antibiotics are often not warranted. The incidence of stomal infection is approximately $5-6 \%$ and usually develops $>24$ hours after tracheostomy placement (36). It is mostly self-limiting and may be managed with local antibiotic therapy (Figure 8). If necrotizing tracheal infection occurs, patients will need systemic antibiotics, airway conversion to an orotracheal intubation, removal of the tracheostomy tube, and surgical debridement $(12,32)$.

\section{Subcutaneous emphysema}

Subcutaneous emphysema can be caused by positive pressure ventilation or coughing against a tightly sutured or packed stomal wound. It can be prevented by not suturing the wound around the tracheostomy tube. Subcutaneous emphysema usually self-resolves within a few days, but a chest radiography should be obtained to rule out a 


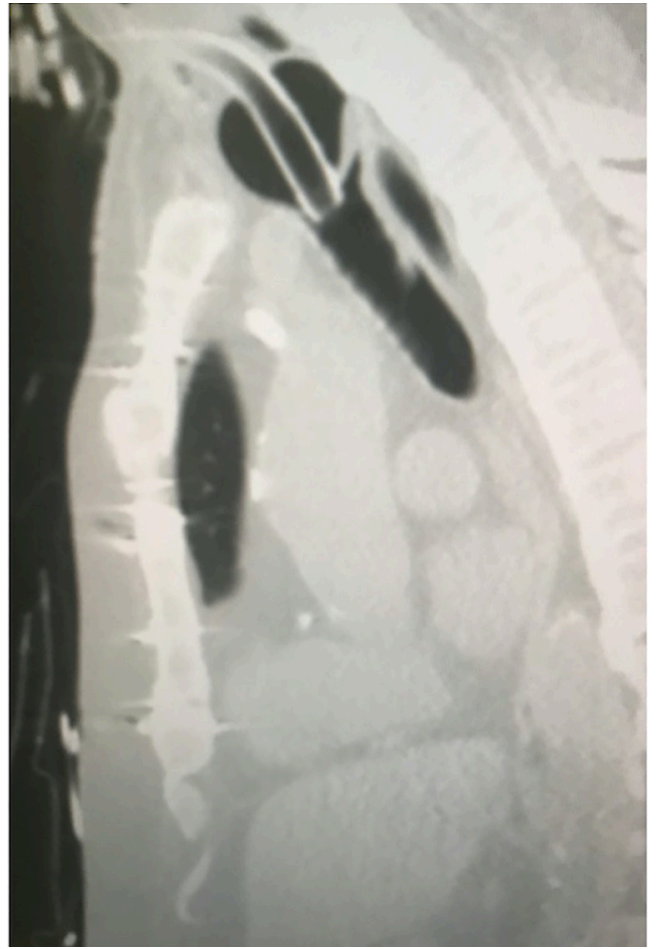

Figure 9 Sagittal CT-image of an over-inflated tracheostomy cuff.

pneumothorax (32).

\section{Complications related to tracheostomy cuff pressure}

Tracheostomy tube cuff pressure should be maintained in the 20-25 $\mathrm{mmHg}$ range. Over-inflation of the cuff beyond $25 \mathrm{mmHg}$ exceeds the capillary refill pressure (Figure 9) and is associated with increased risk of mucosal ischemia, which may lead to mucosal ulceration, necrosis, and development of tracheomalacia, tracheal stenosis, and TIF (37). Underinflating the cuff, $<15 \mathrm{mmHg}$, prevents creating an adequate seal in the trachea and allows upper airway secretions to penetrate the airway, thus increasing the risks of aspiration and pneumonia (20). Cuff pressure should be monitored with a calibrated device and recorded at least once per nursing shift and after each manipulation (32). Estimation of appropriate cuff inflation by palpating the pilot balloon is not reliable and should be avoided (38).

A persistent leak manifests by audible noises around the tracheostomy or loss of returned volume if on mechanical ventilation. A small leak is usually well-tolerated if the patient ventilates adequately. If the cuff continues to require the addition of more air to seal the airway for appropriate ventilation, the pilot balloon may be damaged or ineffective, the tracheostomy tube may be too small for the airway, or tracheomalacia may have developed (39). We recommend the use of bronchoscopy for further evaluation. If the cause is unable to be determined, the tracheostomy tube should be replaced, and the old tube tested for the presence of a cuff leak.

\section{Tracheostomy tube malfunction}

Obstruction secondary to secretions and mucus plugging is the most common cause for tube malfunction. In some cases, it may be due to obstructive blood clots. As mentioned previously, prevention is crucial with appropriate suctioning, use of humidified air, and implementation of airway secretion exercises (21). The IC, if present, can be changed to relieve obstruction, or a bronchoscopy may be performed to clear secretions and identify the cause of obstruction.

Granulation tissue formation at the distal end of the tracheostomy tube is another possible etiology for tube obstruction and can cause airway compromise. This develops secondary to a foreign body reaction to the tube. Granulomas are usually treated with YAG laser or cryotherapy (32). If granulation tissue forms around the stoma site, it could be managed with mechanical removal or the use of local cauterizing agents like silver nitrate (31).

Malposition has a variable presentation, including failure to wean from mechanical ventilation, difficulty or inability to pass suction catheters, and intermittent high peak airway pressures. It is usually related to the tracheostomy tube being positioned high in the airway, thus instead of sitting coaxially, the distal end is abutting the posterior tracheal wall. Tracheostomy tube malposition is reported in up to $10 \%$ of patients (40). Changing the tube to one with a longer internal length often corrects the problem and facilitates weaning from mechanical ventilation in $94 \%$ of reported cases (27). The importance of confirming optimal placement of the tracheostomy tube at the time of the initial procedure can decrease the risk for this complication. Thus, the use of bronchoscopy in PDT is strongly recommended to provide direct visualization of tube positioning (39).

\section{Tracheostomy tube dislodgement or accidental decannulation}

Tube displacement during the early post-operative period ( $<7$ days) can result in partial dislodgement or complete 
decannulation. Predisposing factors include loose TT, neck edema, airway edema, excessive coughing, agitation, undersedation, morbid obesity, tracheostomy tube being too short for the tract, and downward traction from the weight of the ventilator circuit (12). Capnography wave changes can be an early indication of tube displacement (41). It takes approximately 7 days for the tracheostomy tract to mature; thus, the stoma will quickly collapse and close if the tube is displaced or accidentally removed before maturation. The quick collapse of the tissue planes makes the rate of unsuccessful simple replacement high, resulting in a high incidence of false replacement; thus, tracheostomy tube displacement is considered an airway emergency. If dislodgement is suspected, an attempt should be made to pass a suction catheter. If the catheter cannot be passed, then the tube has likely dislodged into a false passage. The tube should be removed, and the patient treated similarly to an accidental decannulation, with bag-mask ventilation and orotracheal intubation. After securing the airway, the tracheostomy can be replaced either percutaneously or surgically $(42,43)$.

\section{Tracheostomy decannulation}

Patients should be routinely assessed for readiness for decannulation (removal of tracheostomy tube). Potential candidates should have an adequate strong cough, be able to protect their upper airway, clear their secretions, and have minimal oxygen requirements. They should not require any mechanical ventilator support for a minimum of 24-36 hours, often longer $(10,20)$. Proposed criteria for decannulation include stable arterial blood gasses, absence of distress, hemodynamic stability, absence of fever or active infection, $\mathrm{PaCO} 2<60 \mathrm{mmHg}$, absence of delirium or psychiatric disorder, normal bronchoscopic airway examination (or stenosis $<30 \%$ ), adequate swallowing, and ability to expectorate (44).

Several methods are available for weaning, including progressively decreasing the tracheostomy tube size, using a tracheostomy plug or button, and capping trials of the tracheostomy. Once a capping trial is tolerated for an extended period, the tracheostomy tube can be safely removed. The site should be cleansed, and an occlusive dressing applied over the stoma. Patients should be instructed to apply pressure over the dressing with their fingers when coughing or talking in order to manually occlude the stoma site. The dressing should be changed daily $(10,20,21)$. The stoma site typically closes within
5-7 days by secondary intention. When tracheostomies have been in place for a prolonged period, epithelialization between the skin and the tracheal mucosa may occur, causing a "persistent stoma" in $2-5 \%$ of patients (45). The stoma will usually decrease in size secondary to wound contracture, but surgical closure may be needed in some cases (32).

\section{Gastrostomy}

Critical illness is a catabolic state that causes nutritional depletion resulting in tissue breakdown, compromised immune function, and poor wound healing (46). Nutritional therapy is a well-accepted and evidence-based adjunctive care that improves the clinical course of critical illness and is an essential part of critical care guidelines (30). Enteral nutrition $(\mathrm{EN})$ is the preferred method of delivery because it is more physiologic, safe, and cost-effective compared to parenteral nutrition. Its only requirement is a functional digestive tract (47).

Nasally placed tubes with their distal tip in the stomach or small intestine are the preferred modality in patients requiring temporary EN support, usually up to 4-6 weeks. When a longer duration of EN support is required, stomal or percutaneous tubes are placed. These include gastrostomy $(\mathrm{G})$ tubes, jejunostomy $(\mathrm{J})$ tubes, and gastrojejunostomy $(\mathrm{G} / \mathrm{J})$ tubes $(46,48)$. Gastrostomy tube placement was originally a surgical procedure until 1980 when Gauderer and Ponsky reported the first successful placement of a percutaneous gastrostomy tube in both children and adults (49). Placing EN tubes endoscopically is the current standard of care unless otherwise indicated. They are placed by gastroenterologists, interventional radiologists (IR), surgeons, and recently by IP (5). Yarmus et al. published a prospective study addressing the safety of PEG tubes placed by IPs that reported a $97.2 \%$ successful placement rate with a $1.4 \%$ complication rate, which were all minor complications (4).

We will discuss early and long-term wound care as well as complications related to the placement of gastrostomy tubes. Caregivers need to be familiar with the different tube components and have a basic understanding of how they are placed and secured to provide adequate care and tube maintenance and to prevent complications.

\section{Feeding tube types}

G-tubes (Figure 10) are usually made of polyurethane 


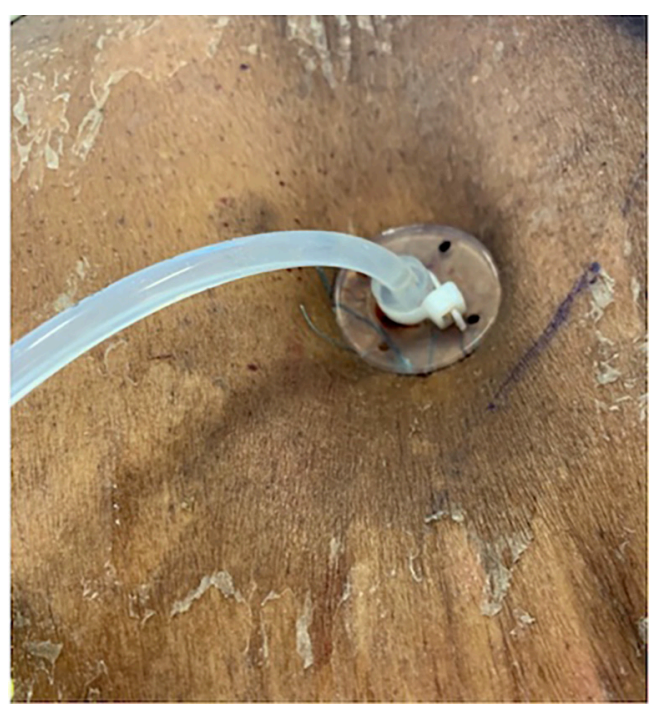

Figure 10 Gastrostomy tube showing bumper in place.

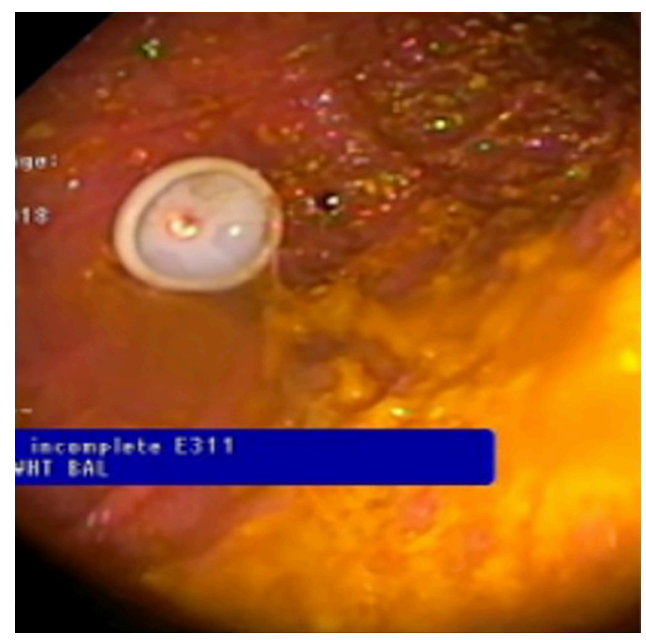

Figure 11 Non-balloon plastic dome of a gastrostomy tube in the stomach.

or silicone and are available in sizes ranging $12-30 \mathrm{Fr}$ in diameter. The inner retention device consists of either an inflatable balloon or non-balloon plastic dome (Figure 11) or mushroom-shaped funnel. Standard G-tubes have a visible tube exiting the abdomen, and low profile "button" tubes are flush at skin level. Standard tubes have a plastic external retention device, usually referred to as the bolster, disc, bumper, flange, or anchor, that can be moved along the tube and is fitted about a dime's width from the skin. For tubes without such devices, securement to the abdominal wall is achieved with adhesive, steri-strips, tape, or sutures (46). Regardless of the type of fixation, the external length of the tube should be marked, documented, and periodically checked. Balloon G-tubes usually require replacement every 3-4 months, and non-balloon G-tubes, every 6-12 months per the manufacturer's recommendations.

J-tubes can either be placed directly into the jejunum only [percutaneous endoscopic jejunostomy (PEJ)] or as trans-gastric jejunostomy tubes (G/J-tube). G/J-tubes have two ports: (I) the proximal opening at the level of the stomach, which is usually used for decompression and medication administration, and (II) the second distal opening will extend into the jejunum, which is used for feeding (50). The type of tube placed should be clearly communicated and documented in the patient's chart.

Patients should fast for at least 6-8 hours prior to the procedure to minimize aspiration risk. Appropriate lab work, including recent coagulation studies, should be available. This is to ensure no thrombocytopenia or coagulopathy are present since PEG is considered a high-risk procedure for bleeding. Anticoagulation and antiplatelet medications need to be reviewed, and based on the patient's risk profile, the need to hold or bridge with heparin will be addressed $(51,52)$. Pre-procedure prophylaxis with antibiotics is recommended as it effectively reduces the incidence of stomal infection. A single dose of a beta-lactamase antibiotic one hour prior to the procedure is recommended. In areas where methicillin-resistant S. aureus (MRSA) is prevalent, vancomycin may be used $(47,53)$.

\section{Gastrostomy tube care}

\section{Using the newly placed PEG tube}

While PEG tubes may be used immediately after placement if cleared by the placing provider, it is recommended to wait 3-6 hours before administration of small amounts of water or nutritional formula. Intake is progressively increased to the fully prescribed volume within $48-72$ hours. This is a change from prior recommendations to wait 12-24 hours post-PEG placement prior to any use (54). A systematic review from Bechtold et al. concluded that early feeding at 3-6 hours had no significant difference in rates of site infections, diarrhea, bleeding, GERD, fever, vomiting, stomatitis, leakage or death. In addition, early feeding is safe, well-tolerated, and reduced costs and hospital length of stay when compared to delayed feeding (55). Each institution should have their own protocols, and nursing 
staff should be familiar with them.

\section{Stoma and catheter care}

The stoma, tube, and external retention device should be cleaned daily with mild soap and warm water, then welldried. In the first 1-2 weeks, an antiseptic or antibiotic ointment may be applied based on the provider's instructions. The tube should be covered with sterile gauze during that period with care taken not to apply it too tightly that it presses into the patient's skin. A dressing (usually split gauze) between the skin and external fixator should not be placed unless it is needed for excessive drainage. The patient may shower in one week if there are no signs of inflammation present $(54,56)$.

Daily rotation of the tube 360 degrees both clockwise and counterclockwise is recommended to prevent decubitus ulcers from forming between the abdominal and gastric walls. This can result in serious complications, including tissue necrosis and buried bumper syndrome (BBS). G/J and surgically placed J-tubes, however, cannot and should not be rotated since this can lead to tube displacement, hollow organ damage, and/or perforation $(46,54,56)$.

\section{Feeding and medication administration}

Nutritional formulas should be used rather than grinding regular foods. The appropriately prescribed formula and addition of free water are tailored to individual nutritional needs. Formula can be administered at room temperature with the use of a syringe, gravity, or low-pressure feeding pump as continuous or bolus feeding. In most ICUs, tube feeding is given as a continuous feed. The head of the bed is elevated at $30-45^{\circ}$ during feeds and for an hour afterwards (if bolus feeding is used) to facilitate gastric emptying and prevent GERD and aspiration. Flushing the feeding tube regularly every $4-6$ hours with $30-50 \mathrm{~mL}$ of warm water and after feeds or medication administration prevents residues from blocking the tube (57). When administering medications, the liquid formula should be used when available, tablets should be crushed and completely dissolved in $10-15 \mathrm{~mL}$ of water prior to administration, pills should not be mixed, and enteric-coated or long-acting extended-release formulas should not be given via PEG as crushing them interferes with their mechanism of action and medication release (57).

Limited evidence is available on the safety and tolerability of $\mathrm{EN}$ in the prone position. Head of bed elevation at $25^{\circ}$ along with the use of pro-kinetic agents and small bowel feeding (J-tube) have shown to increase volume tolerance and progression to feeding goals. Standard nursing care including regular assessment of secretion clearance, oral hygiene, abdominal exam every 4 hours and as indicated, use of prokinetic agents, and transpyloric tube placement are recommended (57).

\section{Checking gastric residual volume (GRV)}

Multiple studies demonstrated benefits of checking GRV in ICUs to prevent aspiration events. Other studies have shown poor correlation between GRV and gastric emptying. The cutoff for holding EN is also variable, ranging from $>250$ to $>500 \mathrm{~mL}$; however, decreasing the cutoff did not change the aspiration risk. In fact, it led to unnecessary interruptions in feeding, delay in meeting nutritional needs, and higher tube obstruction rates. Three trials [2 RCTs $(58,59)$ and 1 prospective before/after implementation trial (60)] showed no significant change in pneumonia rates related to GRV. The 2016 guidelines endorsed by the Society of Critical Care Medicine (SCCM) and American Society for Parenteral and Enteral Nutrition (A.S.P.E.N) recommend against monitoring GRV as part of routine care in ICU patients receiving EN. In ICUs in which GRVs are still obtained, holding EN for GRV $<500 \mathrm{~mL}$ in absence of other signs of intolerance should be avoided. Although this is based on low quality evidence, they support the use of daily physical exam for monitoring signs of EN intolerance (56).

\section{Gastrostomy wound-related complications}

Gastrostomy tube placement is considered a safe procedure with low complication rates ranging between $0.4-22.5 \%$. Minor complications are three times more common (61). Complications can be subdivided into minor (granuloma formation, wound infection, catheter obstruction, stomal leak, gastric outlet obstruction, diarrhea/constipation, and failure of stoma closure post removal) and major (hemorrhage, ileus, injury to intra-abdominal organs, necrotizing fasciitis, aspiration, BBS, tumor harvesting, and volvulus) groups (47). The most relevant complications are highlighted next.

\section{Bleeding}

Bleeding post-placement is rare-major bleeding requiring 


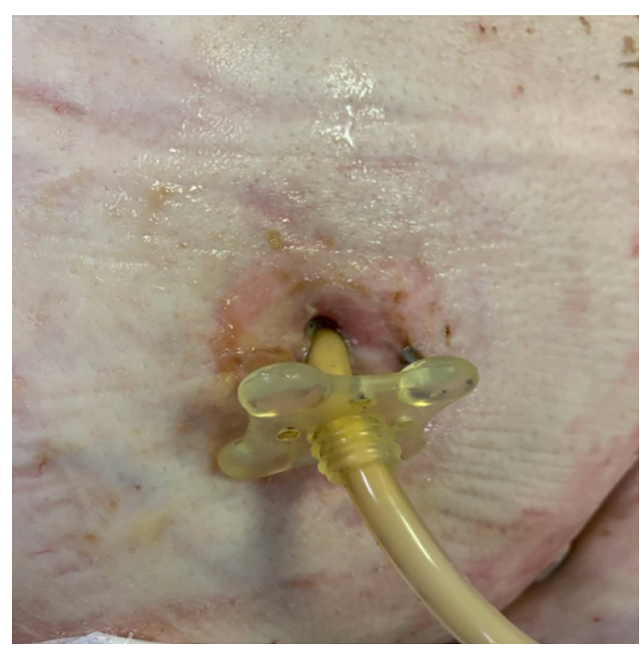

Figure 12 Infected PEG site with erythema and drainage.

transfusion or endoscopic or surgical intervention occurs in $2.5 \%$ of cases. The source of bleeding can originate from the abdominal wall, along the gastrostomy route, or from lesions in major local vessels (gastric and splenic arteries, mesenteric veins). It is an early complication manifesting as peristomal hemorrhage, hematemesis, and hemodynamic instability. Evaluation and management of bleeding may require endoscopy, CT imaging, or even surgical exploration (62).

\section{Tube leakage}

It is expected for newly placed tubes to have small amounts of drainage with variable color. If the drainage amount is excessive, then tube position and internal balloon inflation (if present) should be evaluated. There are no current published guidelines to specify what amount constitutes small $v s$. excessive drainage. The position of the external fixating device (bolster, disc, bumper, flange, anchor) should also be checked and repositioned if needed. If the tube continues to leak despite these interventions, the clinician will need to review tube positioning and consider distal placement, such as a J-tube. Patients should be started on antacid treatment (e.g., proton-pump inhibitor) to decrease skin irritation secondary to the acidic gastric contents. Barrier creams or absorptive powders containing zinc-based products also serve the same purpose. After application, the site is covered with a split-gauze dressing. Non-alcoholic skin barrier films or skin barrier wafers can also be used (46).

After the initial tube placement, tissue swelling is expected. When the swelling recedes, persistent leakage may occur if the initial incision was too wide or if feeding was administered too rapidly. Management includes confirming proper tube placement and titrating feeding. Placement of larger gauge gastrostomy tubes should be avoided because it can dilate the stoma further without promoting tissue healing $(46,63)$.

\section{Tube site infection}

Localized erythema is common after new tube placement. If this persists or increases in size, the stoma site needs to be evaluated for infection. This includes observing for redness, induration, edema, pain, and fever (Figure 12). If there is drainage, the color does not necessarily correlate with infection since normal gastric fluid color is variable and may be green. If infection is suspected, antibiotic ointment can be applied, and systemic antibiotics are needed in some cases (46). If scattered, red, raised papules are seen forming from the stoma outwards, fungal infection should be suspected. Topical antifungals such as nystatin powder or cream can be applied locally and covered with a zinc oxide cream coating followed by a split gauze dressing. Twice daily dressing changes are recommended (46). Consultation with a wound care specialist is also advised.

Necrotizing fasciitis is a rare but severe form of infection that can develop at the stoma site. The infected peristomal soft tissue can be edematous, erythematous, painful, and associated with fever and bullae formation. Risk factors for necrotizing fasciitis include malnourished, immunosuppressed states and excessive traction pressure of the gastrostomy orifice (64). Treatment involves administration of broad-spectrum intravenous antibiotics and urgent surgical debridement (47).

\section{Hypertrophic or granulation tissue formation}

Over time, reddened, lumpy, moist tissue growth may develop at the stoma site, referred to as hypertrophic or granulation tissue. It can lead to increased site drainage, which further promotes tissue formation. Treatment is usually dissolution, commonly with silver nitrite applicators and topical steroid creams. Care should be taken to avoid steroid application to the healthy skin around the granulation tissue as it can cause skin thinning over time. Lastly, surgical removal can be considered $(46,65)$. 


\section{Buried bumper syndrome}

BBS is a condition in which the internal fixation device migrated outside the stomach and is impacted on the gastric wall or skin. It is a very rare complication occurring in $1.5-1.9 \%$ (66) of patients and usually occurs in the first four months of using the tube. The excessive tension between the external and internal fixators can lead to tissue ulceration, ischemia and necrosis. BBS can be complicated by hemorrhage, gastric perforation, and peritonitis. Diagnosis is made through direct visualization and physical examination. Upper endoscopy is used to directly assess the extent of migration, and treatment is mainly endoscopic or surgical. Prevention by avoiding tension between the fixators and daily tube rotation is paramount (61).

\section{Tube blockage}

Tube blockage is a common occurrence with an incidence of $23-35 \%$ (67). Proper tube care in relation to feeding and medication administration as detailed earlier is key to prevention. If obstruction still occurs, the first step is to infuse $50-60 \mathrm{~mL}$ flush of warm water with a back-and-forth plunger movement to help loosen up the clog. The use of a carbonated beverage should be avoided as this can worsen the obstruction by denaturing proteins from the enteral formula present in the tube. Another method is using water penetration. First, withdraw any fluid that is in the tube, then instill $30-60 \mathrm{~mL}$ of warm water and leave the syringe attached for 30-60 minutes while periodically moving the syringe back-and-forth to help dislodge the blockage.

If the prior two methods are unsuccessful, then a mixture of pancreatic enzymes activated by baking soda and warm water can be used in a similar technique to the water penetration method. The mixture is usually made by dissolving a crushed $650 \mathrm{mg}$ non-enteric coated sodium bicarbonate tablet or a quarter teaspoon backing soda in $10 \mathrm{~mL}$ of warm water, then adding the contents of a $12,000 \mathrm{U}$ pancrelipase capsule (Creon ${ }^{\circledR}$ ) or a crushed 10,440 U pancrelipase tablet (Viokace ${ }^{\circledR}$ ), and allowing it to dissolve before instilling it into the tube. This can be repeated once. If still unsuccessful, then the tube may need to be replaced. This is also used sometimes as a prophylactic lock to prevent sludge buildup in high-risk tubes $(46,68)$.

\section{Tube dislodgement}

Tube dislodgement occurs in $>12 \%$ of patients with chronic
PEG tubes and is a common reason for emergency room visits (69). It takes $2-4$ weeks post placement of a firsttime tube for the tract to mature; however, this can be delayed in patients with impaired wound healing, such as immunosuppressed or diabetic patients. If the tube is dislodged before tract maturation, patients are at an increased risk of complications, including peritonitis and false passage, especially when not replaced by a health care provider. Management will usually require endoscopic assistance for replacement. If the tube is dislodged after tract maturation ( $>4$ weeks), it could be replaced directly without endoscopy. Stoma closure occurs within 1-4 hours; thus, a $16-18$ Fr Foley may be placed temporarily to keep the stoma patent until the PEG tube becomes available. If there is a concern about appropriate placement, watersoluble contrast injected through the tube can be used to confirm placement radiographically $(47,50)$.

\section{Gastrostomy decannulation}

When the gastrostomy tube is to be removed, patients should be kept NPO for at least 4 hours prior to the procedure. The stoma and tube should be lubricated, and any secretions within the tube should be suctioned out. The balloon (if present) should be deflated. The tube is removed by direct gentle pulling with one hand while placing the second hand flat against the patient's abdomen for countertraction. The internal fixation device will deconform as it passes through the stoma. In some types of tubes, the internal fixation device is non-collapsible and will require endoscopic assistance for removal. The stoma site should be kept dry and covered. Patients are only allowed sips of water with no food for the first 4 hours after removal (46). On occasion, the stoma tract will not close, and a gastro-cutaneous fistula forms. A trial of thick zinc oxide paste to the opening covered with pressure dressing could be tried before attempting invasive methods, including endoscopic clipping, suturing, plugging, and banding techniques. Surgical fistula closure is also an option (70).

\section{Conclusions}

Tracheostomy and gastrostomy tube placements are common procedures in the critical care setting. These procedures are safe and have low complication rates when performed by an experienced IP physician. Post-procedure care is delivered via a multidisciplinary team, including 
physicians, nurses, respiratory therapists, and caregivers. Proper wound care can help improve patient's quality of life and minimize complications. Standardized care protocols should be developed, and care providers should be familiar with them.

\section{Acknowledgments}

Funding: None.

\section{Footnote}

Provenance and Peer Review: This article was commissioned by the Guest Editors (Jonathan S. Kurman, Ashutosh Sachdeva and Rahul Nanchal) for the series "Interventional Pulmonology in the Intensive Care Unit Environment" published in Fournal of Thoracic Disease. The article has undergone external peer review.

Conflicts of Interest: All authors have completed the ICMJE uniform disclosure form (available at: http:// dx. doi. org/10.21037/jtd-2019-ipicu-13). The series "Interventional Pulmonology in the Intensive Care Unit Environment" was commissioned by the editorial office without any funding sponsorship. JD is an honorarium consultant for Acute Innovations (financial activity not related to the submitted work). The other authors have no other conflicts of interest to declare.

Ethical Statement: The authors are accountable for all aspects of the work in ensuring that questions related to the accuracy or integrity of any part of the work are appropriately investigated and resolved.

Open Access Statement: This is an Open Access article distributed in accordance with the Creative Commons Attribution-NonCommercial-NoDerivs 4.0 International License (CC BY-NC-ND 4.0), which permits the noncommercial replication and distribution of the article with the strict proviso that no changes or edits are made and the original work is properly cited (including links to both the formal publication through the relevant DOI and the license). See: https://creativecommons.org/licenses/by-nc-nd/4.0/.

\section{References}

1. Ernst A, Silvestri GA, Johnstone D, American College of Chest Physicians. Interventional pulmonary procedures:
Guidelines from the American College of Chest Physicians. Chest 2003;123:1693-717.

2. Frutos-Vivar F, Esteban A, Apezteguía C, et al. Outcome of mechanically ventilated patients who require a tracheostomy. Crit Care Med 2005;33:290-8.

3. Quality of Life After Mechanized Ventilation in the Elderly Study Investigators. 2-month mortality and functional status of critically ill adult patients receiving prolonged mechanical ventilation. Chest 2002;121:549-58.

4. Yarmus L, Gilbert C, Lechtzin N, et al. Safety and feasibility of interventional pulmonologists performing bedside percutaneous endoscopic gastrostomy tube placement. Chest 2013;144:436-40.

5. Belanger A, Akulian J. Interventional pulmonology in the intensive care unit: percutaneous tracheostomy and gastrostomy. Semin Respir Crit Care Med 2014;35:744-50.

6. Szmuk P, Ezri T, Evron S, et al. A brief history of tracheostomy and tracheal intubation, from the Bronze Age to the Space Age. Intensive Care Med 2008;34:222-8.

7. Ciaglia P, Firsching R, Syniec C. Elective percutaneous dilatational tracheostomy. A new simple bedside procedure; preliminary report. Chest 1985;87:715-9.

8. Johnson Obaseki S, Veljkovic A, Javidnia H. Complication rates of open surgical versus percutaneous tracheostomy in critically ill patients. Laryngoscope 2016;126:2459-67.

9. Brass P, Hellmich M, Ladra A, et al. Percutaneous techniques versus surgical techniques for tracheostomy. Cochrane Database Syst Rev 2016;7:CD008045.

10. Madsen KR, Guldager H, Rewers M, et al. Guidelines for Percutaneous Dilatational Tracheostomy (PDT) from the Danish Society of Intensive Care Medicine (DSIT) and the Danish Society of Anesthesiology and Intensive Care Medicine (DASAIM). Dan Med Bull 2011;58:C4358.

11. Raimondi N, Vial MR, Calleja J, et al. Evidence-based guidelines for the use of tracheostomy in critically ill patients. J Crit Care 2017;38:304-18.

12. Morris LL, Whitmer A, McIntosh E. Tracheostomy Care and Complications in the Intensive Care Unit. Critical Care Nurse 2013;33:18-30.

13. Hess DR. Tracheostomy tubes and related appliances. Respir Care 2005;50:497-510.

14. Hess DR, Altobelli NP. Tracheostomy tubes. Respir Care 2014;59:956-71; discussion 971-3.

15. Klotz R, Probst P, Deininger M, et al. Percutaneous versus surgical strategy for tracheostomy: a systematic review and meta-analysis of perioperative and postoperative complications. Langenbecks Arch Surg 2018;403:137-49. 
16. Gobatto ALN, Besen BAMP, Tierno PFGMM, et al. Ultrasound-guided percutaneous dilational tracheostomy versus bronchoscopy-guided percutaneous dilational tracheostomy in critically ill patients (TRACHUS): a randomized noninferiority controlled trial. Intensive Care Med 2016;42:342-51.

17. Malata CM, Foo IT, Simpson KH, et al. An audit of Björk flap tracheostomies in head and neck plastic surgery. Br J Oral Maxillofac Surg 1996;34:42-6.

18. Nance-Floyd B. Tracheostomy care: an evidence-based guide to suctioning and dressing changes. Am Nurs Today 2011;6:14-6.

19. Regan EN, Dallachiesa L. How to care for a patient with a tracheostomy. Nursing 2009;39:34-9; quiz 39-40.

20. Mehta C, Mehta Y. Percutaneous tracheostomy. Ann Card Anaesth 2017;20:S19-25.

21. Mitchell RB, Hussey HM, Setzen G, et al. Clinical consensus statement: tracheostomy care. Otolaryngol Head Neck Surg 2013;148:6-20.

22. Cane RD, Shapiro BA. Mechanical Ventilatory Support. JAMA 1985;254:87-92.

23. Siempos II, Vardakas KZ, Falagas ME. Closed tracheal suction systems for prevention of ventilator-associated pneumonia. Br J Anaesth 2008;100:299-306.

24. Freytag CC, Thies FL, König W, et al. Prolonged Application of Closed In-Line Suction Catheters Increases Microbial Colonization of the Lower Respiratory Tract and Bacterial Growth on Catheter Surface. Infection 2003;31:31-7.

25. Sole ML, Byers JF, Ludy JE, et al. A Multisite Survey of Suctioning Techniques and Airway Management Practices. Am J Crit Care 2003;12:220-30.

26. O’Toole TR, Jacobs N, Hondorp B, et al. Prevention of Tracheostomy-Related Hospital-Acquired Pressure Ulcers. Otolaryngol Head Neck Surg 2017;156:642-51.

27. White AC, Kher S, O'Connor HH. When to change a tracheostomy tube. Respir Care 2010;55:1069-75.

28. Yaremchuk K. Regular tracheostomy tube changes to prevent formation of granulation tissue. Laryngoscope 2003;113:1-10.

29. Backman S, Björling G, Johansson UB, et al. Material wear of polymeric tracheostomy tubes: a six-month study. Laryngoscope 2009;119:657-64.

30. Sherman JM, Davis S, Albamonte-Petrick S, et al. Care of the child with a chronic tracheostomy. This official statement of the American Thoracic Society was adopted by the ATS Board of Directors, July 1999. Am J Respir Crit Care Med 2000;161:297-308.
31. Howe N, Cherpelis B. Obtaining rapid and effective hemostasis: Part I. Update and review of topical hemostatic agents. J Am Acad Dermatol 2013;69:659.e1-659.e17.

32. De Leyn P, Bedert L, Delcroix M, et al. Tracheotomy: clinical review and guidelines. Eur J Cardiothorac Surg 2007;32:412-21.

33. Scalise P, Prunk SR, Healy D, et al. The incidence of tracheoarterial fistula in patients with chronic tracheostomy tubes: a retrospective study of 544 patients in a long-term care facility. Chest 2005;128:3906-9.

34. Menen RS, Pak JJ, Dowell MA, et al. Treatment of Tracheoinnominate Fistula with Ligation of the Innominate Artery: A Case Report. Perm J 2016;20:15-166.

35. Shamji FM, Deslauriers J, Nelems B. Recognition and Management of Life-Threatening Tracheovascular Fistulae and How to Prevent Them. Thorac Surg Clin 2018;28:403-13.

36. Delaney A, Bagshaw SM, Nalos M. Percutaneous dilatational tracheostomy versus surgical tracheostomy in critically ill patients: a systematic review and meta-analysis. Crit Care 2006;10:R55.

37. Morris L, Afifi MS. In: Tracheostomies: the Complete Guide. 1st ed. New York, NY: Springer Publishing Company LLC; 2010. p. 211-41.

38. Fernandez R, Blanch L, Mancebo J, et al. Endotracheal tube cuff pressure assessment: pitfalls of finger estimation and need for objective measurement. Crit Care Med 1990;18:1423-6.

39. Gadkaree SK, Schwartz D, Gerold K, et al. Use of Bronchoscopy in Percutaneous Dilational Tracheostomy. JAMA Otolaryngol Head Neck Surg 2016;142:143-9.

40. Schmidt U, Hess D, Kwo J, et al. Tracheostomy tube malposition in patients admitted to a respiratory acute care unit following prolonged ventilation. Chest 2008;134:288-94.

41. Ahrens T, Sona C. Capnography Application in Acute and Critical Care. AACN Clin Issues 2003;14:123-32.

42. Rajendram R, McGuire N. Repositioning a displaced tracheostomy tube with an Aintree intubation catheter mounted on a fibre-optic bronchoscope. Br J Anaesth 2006;97:576-9.

43. O'Connor HH, White AC. Tracheostomy decannulation. Respir Care 2010;5 5:1076-81.

44. Christopher KL. Tracheostomy decannulation. Respir Care 2005;50:538-41.

45. Stelfox HT, Hess DR, Schmidt UH. A North American survey of respiratory therapist and physician tracheostomy 
decannulation practices. Respir Care 2009;54:1658-64.

46. Lord LM. Enteral Access Devices: Types, Function, Care, and Challenges. Nutr Clin Pract 2018;33:16-38.

47. Molina Villalba C, Vázquez Rodríguez JA, Gallardo Sánchez F. Percutaneous endoscopic gastrostomy. Indications, care and complications. Med Clin (Barc) 2019;152:229-36.

48. Itkin M, DeLegge MH, Fang JC, et al. Multidisciplinary practical guidelines for gastrointestinal access for enteral nutrition and decompression from the Society of Interventional Radiology and American Gastroenterological Association (AGA) Institute, with endorsement by Canadian Interventional Radiological Association (CIRA) and Cardiovascular and Interventional Radiological Society of Europe (CIRSE). Gastroenterology 2011;141:742-65.

49. Gauderer MW, Ponsky JL, Izant RJ. Gastrostomy without laparotomy: a percutaneous endoscopic technique. J Pediatr Surg 1980;15:872-5.

50. Johnson TW, Seegmiller S, Epp L, et al. Addressing Frequent Issues of Home Enteral Nutrition Patients. Nutr Clin Pract 2019;34:186-95.

51. Veitch AM, Vanbiervliet G, Gershlick AH, et al. Endoscopy in patients on antiplatelet or anticoagulant therapy, including direct oral anticoagulants: British Society of Gastroenterology (BSG) and European Society of Gastrointestinal Endoscopy (ESGE) guidelines. Endoscopy 2016;48:c1.

52. Alberca-de-Las-Parras F, Marín F, Roldán-Schilling V, et al. Management of antithrombotic drugs in association with endoscopic procedures. Rev Esp Enferm Dig 2015;107:289-306.

53. Allison MC, Sandoe JT, Tighe R, et al. Antibiotic prophylaxis in gastrointestinal endoscopy. Gut 2009;58:869-80.

54. Friginal-Ruiz AB, Lucendo AJ. Percutaneous Endoscopic Gastrostomy: A Practical Overview on Its Indications, Placement Conditions, Management, and Nursing Care. Gastroenterol Nurs 2015;38:354-66; quiz 367-8.

55. Bechtold ML, Matteson ML, Choudhary A, et al. Early versus delayed feeding after placement of a percutaneous endoscopic gastrostomy: a meta-analysis. Am J Gastroenterol 2008;103:2919-24.

56. McClave SA, Taylor BE, Martindale RG, et al. Guidelines for the Provision and Assessment of Nutrition Support
Therapy in the Adult Critically Ill Patient: Society of Critical Care Medicine (SCCM) and American Society for Parenteral and Enteral Nutrition (A.S.P.E.N.). JPEN J Parenter Enteral Nutr 2016;40:159-211.

57. Boullata JI, Carrera AL, Harvey L, et al. ASPEN Safe Practices for Enteral Nutrition Therapy. JPEN J Parenter Enteral Nutr 2017;41:15.

58. Powell KS, Marcuard SP, Farrior ES, et al. Aspirating gastric residuals causes occlusion of small-bore feeding tubes. JPEN J Parenter Enteral Nutr 1993;17:243-6.

59. Reignier J, Mercier E, Le Gouge A, et al. Effect of not monitoring residual gastric volume on risk of ventilatorassociated pneumonia in adults receiving mechanical ventilation and early enteral feeding: a randomized controlled trial. JAMA 2013;309:249-56.

60. Poulard F, Dimet J, Martin-Lefevre L, et al. Impact of not measuring residual gastric volume in mechanically ventilated patients receiving early enteral feeding: a prospective before-after study. JPEN J Parenter Enteral Nutr 2010;34:125-30.

61. Cyrany J, Rejchrt S, Kopacova M, et al. Buried bumper syndrome: A complication of percutaneous endoscopic gastrostomy. World J Gastroenterol 2016;22:618-27.

62. Hucl T, Spicak J. Complications of percutaneous endoscopic gastrostomy. Best Pract Res Clin Gastroenterol 2016;30:769-81.

63. Schrag SP, Sharma R, Jaik NP, et al. Complications related to percutaneous endoscopic gastrostomy (PEG) tubes. A comprehensive clinical review. J Gastrointestin Liver Dis 2007;16:407-18.

64. Cave DR, Robinson WR, Brotschi EA. Necrotizing fasciitis following percutaneous endoscopic gastrostomy. Gastrointest Endosc 1986;32:294-6.

65. Borkowski S. G tube care: managing hypergranulation tissue. Nursing 2005;35:24.

66. El AZ, Arvanitakis M, Ballarin A, et al. Buried bumper syndrome: low incidence and safe endoscopic management. Acta Gastroenterol Belg 2011;74:312-6.

67. Stumpf JL, Kurian RM, Vuong J, et al. Efficacy of a Creon delayed-release pancreatic enzyme protocol for clearing occluded enteral feeding tubes. Ann Pharmacother 2014;48:483-7.

68. Sriram K, Jayanthi V, Lakshmi RG, et al. Prophylactic locking of enteral feeding tubes with pancreatic enzymes. JPEN J Parenter Enteral Nutr 1997;21:353-6. 
69. Rosenberger LH, Newhook T, Schirmer B, et al. Late accidental dislodgement of a percutaneous endoscopic gastrostomy tube: an underestimated burden on patients and the health care system. Surg Endosc 2011;25:3307-11.
70. Tang S. Endoscopic Management of Gastrocutaneous Fistula Using Clipping, Suturing, and Plugging Methods. Video Journal and Encyclopedia of GI Endoscopy. 2014;2:55-60.

Cite this article as: Alsunaid S, Holden VK, Kohli A, Diaz J, O'Meara LB. Wound care management: tracheostomy and gastrostomy. J Thorac Dis 2021;13(8):5297-5313. doi: 10.21037/ jtd-2019-ipicu-13 